مجلة جامعة الملك عبدالعنيز: الاقتصاد الإسالامي، م31 ع3، ص ص: 81-98 (محرم 1440/ أكتوبر 2018) DOI:10.4197/Islec.31-3.5

\title{
أثر الوثيقة الوقفية في الحفاظ على الدور التنموي للأوقاف
}

\author{
عبدالله بن ناصر السدحان \\ نائب رئيس مجلس الإدارة

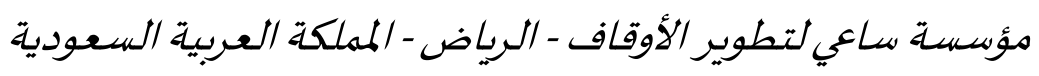

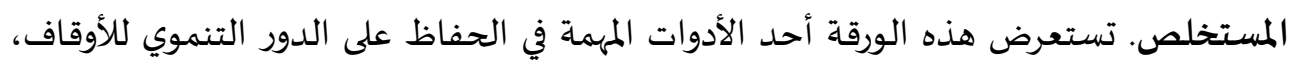

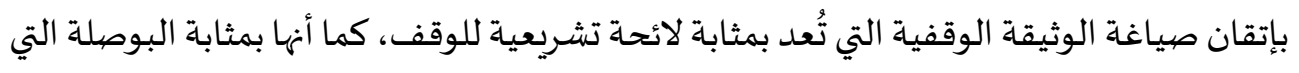

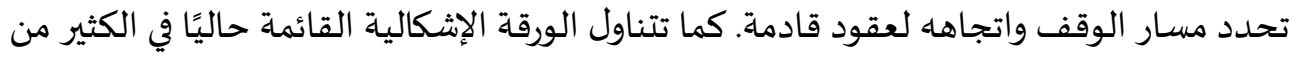

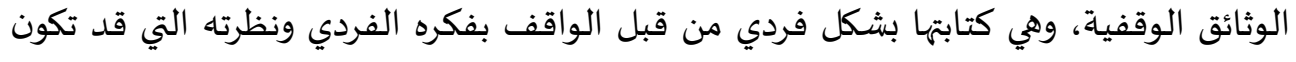

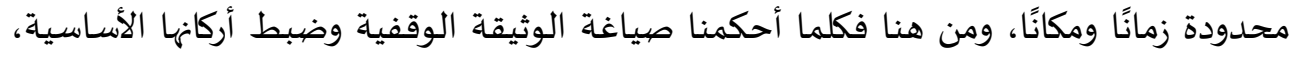

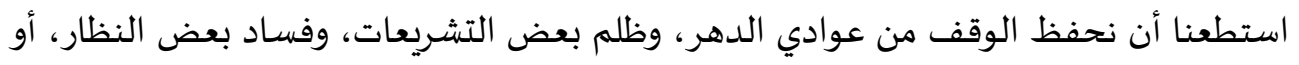

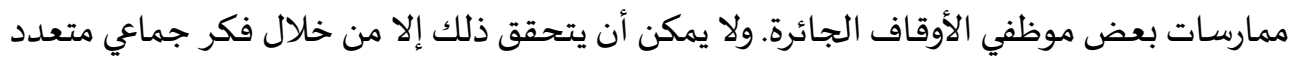

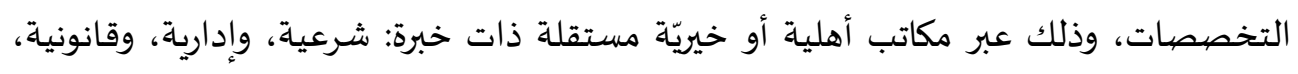

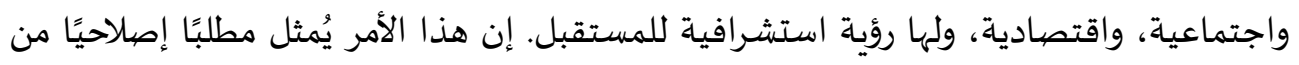

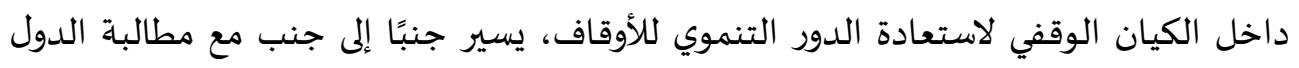
بالتشريعات الحامية، والمطمئنة للواقفين.

الكلمات الدَّالة: الأوقاف، التنمية الاجتماعية، التنمية الشاملة، الوثيقة الوقفية، النظارة الجماعيّة، مصارف الوقف، استثمار الوقف. تصنيف E22, E23:KAUJIE 


\section{مدخل}

يمكن القول: قد تكون النظم والتشريعات الوقفية جيدة والحماية الحكومية مُتحققة، لكن الوقف في ذاته، ومن داخله هش بسبب هشاشـة وثيقته الوقفية، التي أوجدت

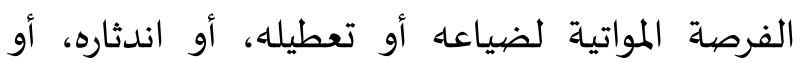
الاستيلاء عليه. ومن هنا كان هذا الطرح الذي ينشد تحقيق التماسك الداخلي للوثيقة الوقفية حتى نُقلل من هن هن تأثير العوامل الخارجية، ونضيمن استمرار ثمرته لأطول فترة ممكنة، وحتى لا يتسع الموضوع سيكون التركيز على الوضع في المملكة العربية السعودياة، مسايرة لما يراه الدكتور محمد موفق الأرناؤوط من أن هناك عدد من

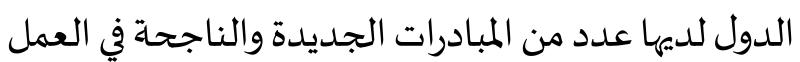
الوقفي ومن تلك الدول المملكة العربية السعودياة. 1- المسيرة الوقفية تتطلب النقد الذاتي لا شك في أن ما ذكره الدكتور محمد موفق الأرناؤوط في بحثه لله أثر بارز في إيجاد دور فاعل للأوقاف، من خلال قوة التشريعات الحامية للوقف وتحقيق الاستثمارات الناجحة للأوقاف، وهو طرح علمي، كثيرًا ما يتردد في الأدبيات الوقفية، وهناك مؤلفات مخصصية للحديث عنـه بتفصيل مطول أحيانًا. وهو طرح له وجاهته بالفعل، لكن تواصل الطرق على هذا الباب تسبب في نسيان الأسباب الأخرى لعدم تحقيق الوقف لدوره التنموي المأمول وهو ما لـا تطرحه هذه الورقة وهو بمثابة ممارساة (النقد الذاتي) للوقف، والمقصود آليات تحقيقه وليس الوقف ذاته، وستكون من باب التشخيص لجانب من جوانب القضية

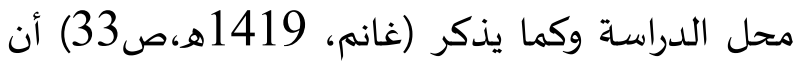
معظم الدراسات المتعلقة بالأوقاف يغلب عليها الأسلوب الوصفي بعيدًا عن المنهج التحليلي وتناول كل دراسة جانبًا

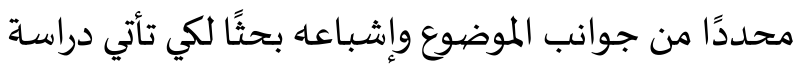

يطرح المنتدى تساؤلاً كبيرًا وهو كيف نصل إلى (دور فاعل للأوقاف في حياة المجتمعات المسلمة المعاصرة)؛ وقد أجاب الدكتور/ محمد موفق الأرناؤوط على هذا التساؤل

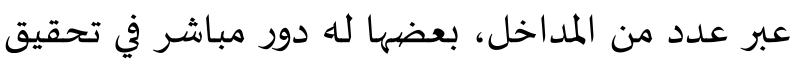

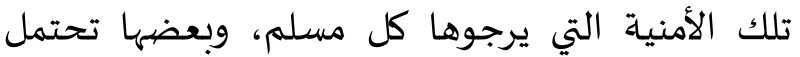
وجهات النظر، فقد ركز على الجانب التشريعي المتمثل في تعديل القوانين بما يُخفف من تدخل الدولة، بالإضيافة

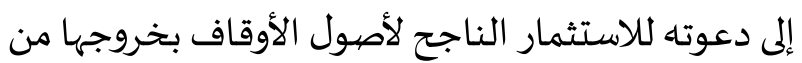
وزارت الأوقاف، واستعادة الدور الأمثل للأوقاف الذريّة. في هذه الورقة سيتمّ طرح مدخل جديد يتيحه المناخ

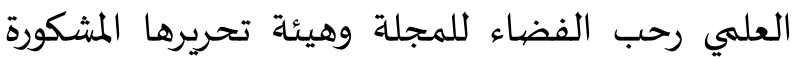
بتشريفي بهذه المشاركة، وكم كان الأنسب أن عنوان المنتدى خلا من كلمة (المعاصرة) فالدور المنتظر للأوقاف يشمل المجتمعات المسلمة المعاصرة، وكذلك القادمة بعد المعاهد عشرات ومئات السنيّن، وهذا ما يُميز المشروع الوقفي في

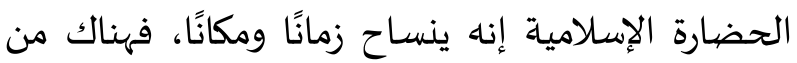
الأوقاف ما تطاول باه العمر حتى بلغ مئات السنين، وشمل منافعاء المجتمع المعاصر للواقف، ومجتمعات عدة تالية لحياة الواقف بقرون، والأمثلة كثيرة في هذا الباب. بداية يمكن تمثيل الوقف - أي وقف - بالبذرة التي تحتاج إلى بيئةٍ صالحةٍٍ مناسبةٍٍ لكي تنمو وتربو بثمارها

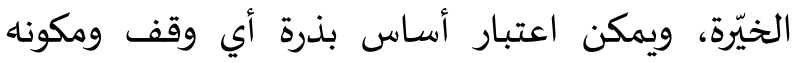
الأساس هو الوثيقة الوقفية وصياغتها، والبيئة الصالحة ولية هي النظم والتشريعات التي ترعى هذا الوقف وتساعد على نموه، كما هو الشأن في عالم النبات. فكم من بذرة صالحسة

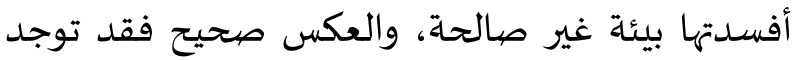
بيئة مناسبة، ولكن البذرة في الأسساس غير صالحة فلا فائدة تُرجى أو أمل يُنتظر من ثمرتها حينئذ، ولتوضيح ذلك الك 
دون أن يكون هناك أي إشارة في الوثيقة الوقفية لتخصيص نسبة من الريع لتنمية الوقف وتثميره ألا يجعله لقمة سائغة لنظارة فاسدة، وبخاصية إذا كانت النظارة

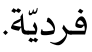
إن من الأمور المؤلمة أن الوثيقة الوقفية كانت - وما تزال تُكتب حين تُكتب بشكل فردي وبرؤية فردية، فقد لا تتجاوز تلك النظرة الفرديّة عشرات سنين قادمة على أقصى تقدير سواءً في مصارفه أو إدارته، أو تثميره. إن وجود مثل هذه الوثيقة الوقفيّة ذات الصياغة غير المُحكمة والتي تكون محدودة الرؤية زمانًا ومكانًا ومصرفًا لا يمكن تجاهل دورها في تعطيل دور الوقف على المدى البعيد، وتناقص غلته أو ضيق مصارف غلته مما يجعلها تكون عائقًا في سبيل تحقيق الاستدامة الوقفية، وبخاصة أن عصرنا يتميز بتسارع في التغيرات، والمستجدات مما يترتب عليه تبدل سريع في الاحتياجات كذلك، وقد يكون من حكمة الله في التعاملات الوقفية أن الذي ورد في السنة حول الوقف هو حكم إجمالي عام في أن يحبس أصل الموقوف وتسبيل ثمرته كما في حديث ابن عمر رضي الله عنهما المتفق عليه(1)، "أما تفاصيل أحكام الوقف المقائ المقررة في الفقه فهي جميعًا اجتهادية قياسية للرأي فها مجال" (الزرقا، 1419هـ، صهاي 19).

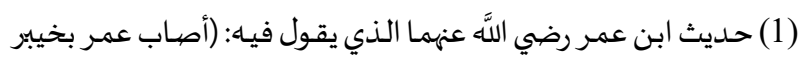

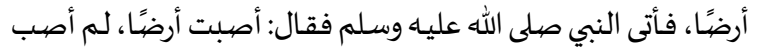

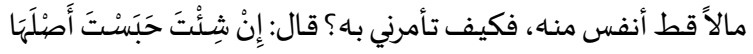

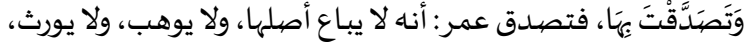

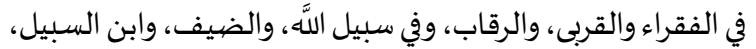

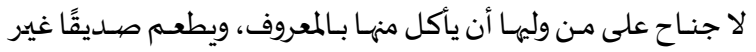

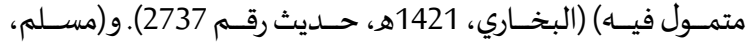
1421هـ، حديث رقم 4224). واللفظ للبخاري.
أخرى لجانب آخر، وهكذا بحيث يحدث تراكم علمي ومعرفي مُنظم حول مختلف جوانب الموضوع مما يسمح بإجراء دراسات تحليلية ومقارنة أكثر تعمقًا. إن من نافلة القول: إن تناول هذا الجانب من موضوع الدراسة وهو نقد الوقف من الداخل، ليس فيه تبرئة للحكومات وتشربعاتها المُعطلة، أو ممارسات موظفيها الجائرة - أحيانًا - تجاه الأوقاف، لكن عين الحكمة تتطلب ضرورة المراجعة الشاملة لمنظومة الوقف بما فيها ممارسات الواقف نفساه خلال صياغة وثيقته الوقفية التي يرى (الحوراني، 2010م، ص240) أنها "بمثابة لائحة تشريعية يلتزم بها ناظر الوقف، ولكن لا يخفى أن إدارة الوقف إذا كانت مقبولة على أساس شرط الواقف في حالة النماذج الوقفية البسيطة فإها لا تكون كذلك في حالة وجود وقفيات عابرة للبلدان سيما وأن الواقف ليس بالضرورة أن يكون مستوعبًا لجانب الإدارة فكرًا وممارسـة". إن الوثيقة الوقفيّة تعتبر بوصلة للوقف، وهي التي تحدد مسـاره ومستقبله البعيد جدًا، بل يمكن التنبؤ بسهولة بمستقبل أي وقف وديمومته، أو تعطله، أو اندثاره، من خلال صياغة الوثيقة الوقفية لله، فقد يكون في ثناياها ما يحقق لها العمر الطويل، وقد يكون في صياغة بعض عباراتها الوثيقة ما يكون بداية نهايته، دون أن يشعر الواقف، فعلى سبيل المثال مُحسن يوقف مدرسة دون رصد أوقاف مُدرة تضيمن استمرارها بعد وفاته، ألا يمكن التنبؤ أنها سوف تضمحل بعد وفاة الواقف، أو من يوقف وقفًا مُدرًاً ولكن لا يحدد نسبة لتنمية الوقف، ألا يمكن التنبؤ بما سيؤول إليه الوقف بعد عشرات السنين نتيجة استنزاف غلته مع مرور السنين، أو من يُوقف وقفًا ضخمًا يدر غلة كبيرة، ومصهارف الوقف محدودة جدًا، ومن ثَمَّم تتوافر مبالغ ضخمة جراء الريع التراكمي بمرور السنين، 


\section{2- قوة الوقف من قوة الوثيقة الوقفية}

لما بعد عشر أو عشرات السنين، فغالبًا ما تُكتب الوثيقة

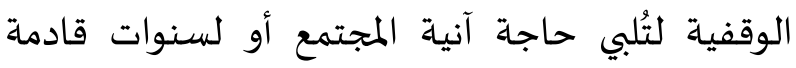
بحسب رؤية الواقف. لوفيك لوني

لقد اجتهد الأولون في صياغة وثائقهم الوقفيّة، وكانت

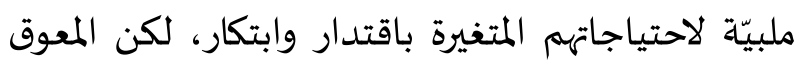
الذي جرى بعد ذلك هو الاستمرار على الصياغات نفسها

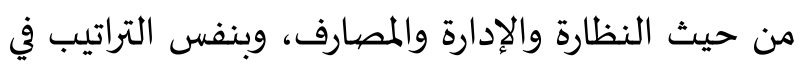

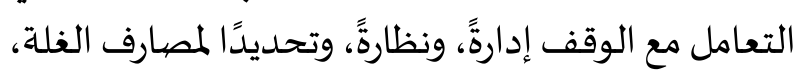

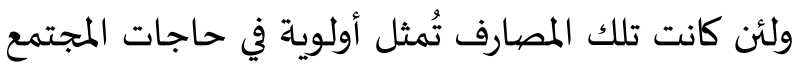

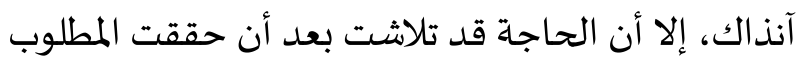

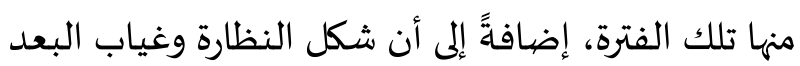

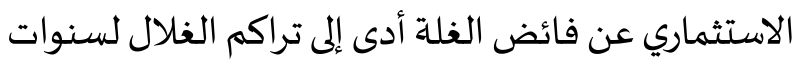

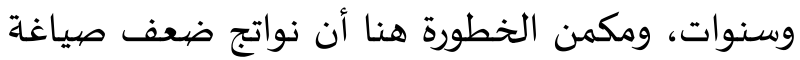

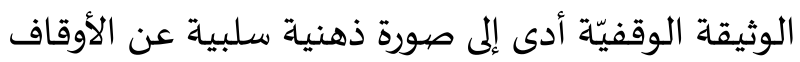

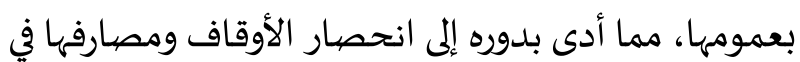
مجالات ضيقة لتستمر الدورة في حركة مؤثرة ومتأثرة في

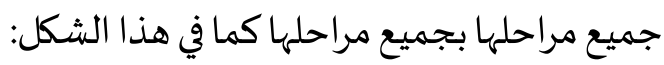

تُعد الوثيقة الوقفيّة وطريقة صياغتها هي المكون الأسـاس الذي يُحدد مسار الوقف لعقود طويلة، وذلك بما تتضيمنه من تفاصيل وخطوات إجرائية في طريقة النظارة،

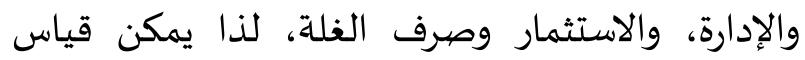
الوقف وقوته وصيموده في مواجهة عوادي الدهر وظلما وهلم بعض التشريعات من خلال قوة صياغة الوثيقة الوقفيّة وإحكامها، ولكن مما يؤخذ على العديد من الوثائق الوقفيّة

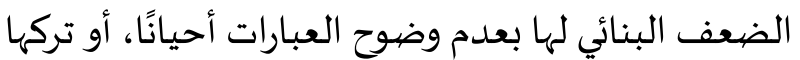

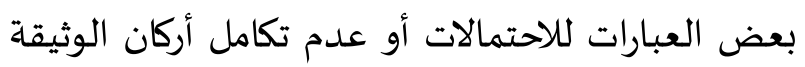

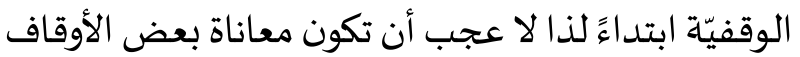

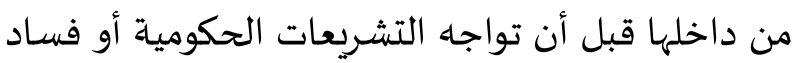

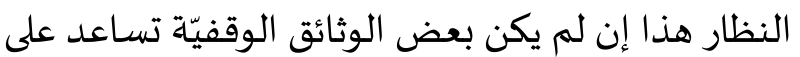

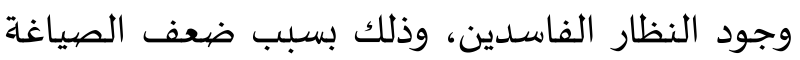
وهشاشتها في التراتيبية الإدارية والتنظيمية ودودية وغياب الحوكمة للتعامل مع الوقف، وعدمث تحوطها للمستقبل؛

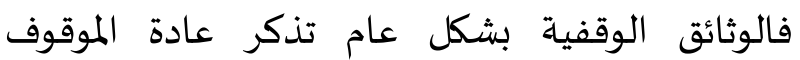

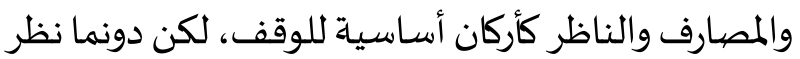

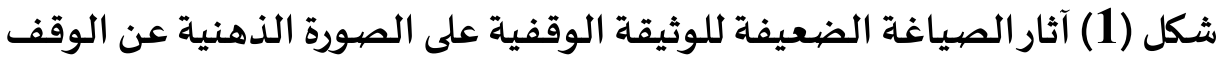

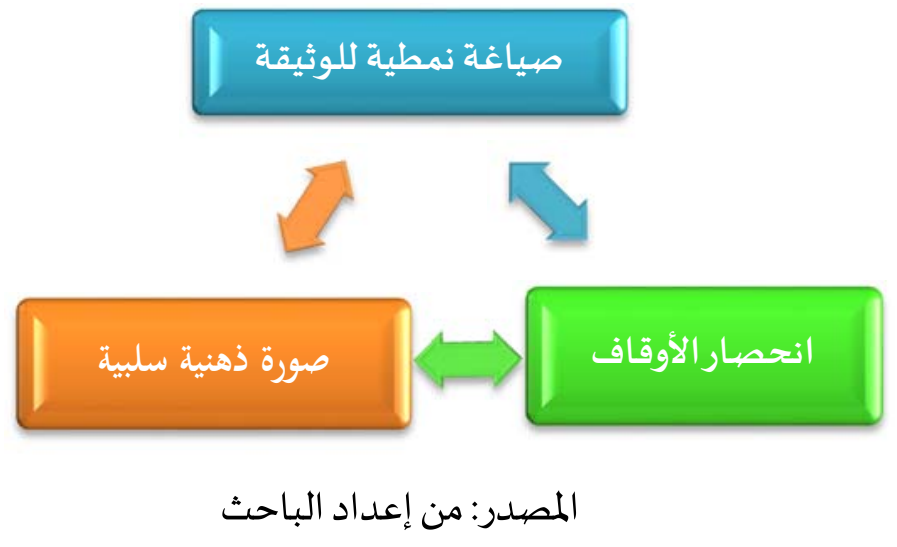

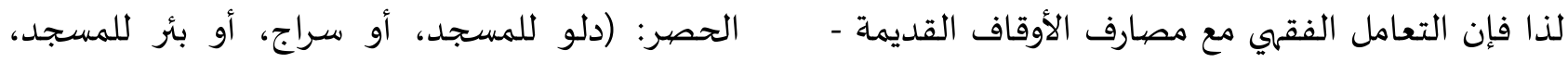

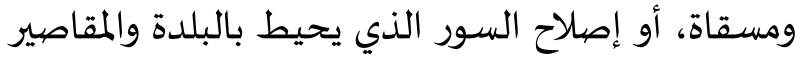

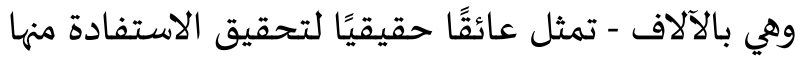

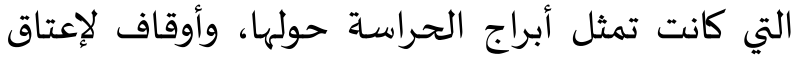

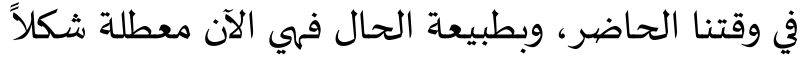

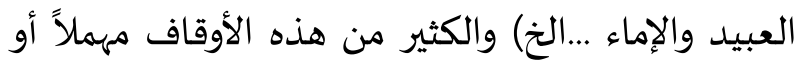

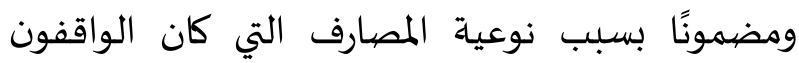
تعطل أو اندثر أو في الطريق إلياء.

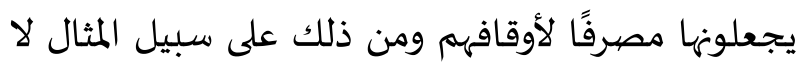


المحكمة للوثيقة الوقفية عبر خبير أو خبراء في المجال وليس من قبل الواقف بمفرده، وبعد ذلك تكون إدارة الوقف والإشراف عليه من خلال نظارة جماعية وحبك منظومة الدورة الإدارية وحوكمتها، وتحقيق الشفافية فيها، للوصول إلى مأسسة حقيقية للعمل الوقفي تجاري المسيرة الإدارية العالمية، فضلاً عن "الاستقرار الإداري والمالي للمؤسسة الوقفية باتباع نظم العمل (سياسات وقواعد وإجراءات)، إضيافة إلى الالتزام بمنظومة من القيم والمبادئ التي تميز الأداء الإداري للمؤسسة الوقفية، والقدرة على رفع الكفاءة الإنتاجية لأموال الأوقاف إلى حدها الأمثل لتعظيم إيرادات المؤسسة الوقفية لأجل الوفاء بالتزاماتها" (الحنين، 2018م ، ص 369).

\section{4- و اقع الوثائق الوقفية الحديثة في المملكة العربية السعودية}

يلاحظ في كثير من الوثائق الوقفيّة الحديثة في المملكة العربية السعودية، غَلبة نوعٍ واحدٍ من المصارف على بقية حاجيات المجتمع، فلا يمكن أن يغيب عن الراصد تركز المصارف في مجالات محددة. ففي تقرير حديث صدر عن لجنة الأوقاف في غرفة الشرقية (2018م)، تمّّ فيه دراسة عينة من الوثائق الوقفية الموثقة عام (1437هـ) من خلال المكاتب الأهلية المتخصصة في الأوقاف، وبلغ عدد تلك الوثائق التي تمّ تحليلها (569) صيًا وقفيًا في كل من: مدينة الرياض، والمدينة المنورة، والدمام(2)، حيثُ رصد التقرير التوجه الصرفي للأوقاف أكثر من (30) ثلاثين مصرفًا،

(2) التقرير يتحدث عن العامين (1437هـ/1438هـ) ولكن تمّ الاقتصيار على إنى

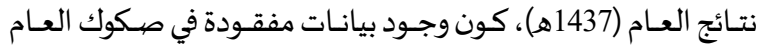

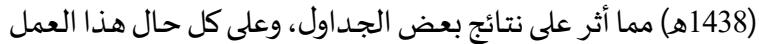

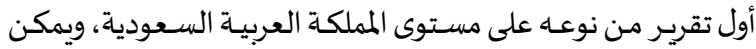

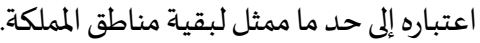

3- إحكام الوثيقة الوقفيّة تُمثل السياج الآمن له تُعد الصياغة الجيدة للوثيقة الوقفية بمثابة الحوامي الشرعية والقانونية للوقف ذاته، ومن هنا لا بد أن تحتوي على تفاصيل كثيرة في الأركان الأساسية للوقف من حيث تحديد النظارة وشكلها (فردي، جماعي) وكيفية عمل تلك النظارة وآلية تتابع النظارة لعقود طويلة بحيث تكون بشكل سلس وغير معطل للوقف، وما هو مخول للنظارة، لتقليل الرجوع إلى جهات أخرى خارج دائرة الوقف ونظارته وإدارته التنفيذية، فعلى سبيل المثال، أحد الأوقاف المحلية في المملكة تعطل عدة شهور لعدم قدرة إدارته التنفيذية فتح حساب في البنك، لأن صك الوقفيّة لم يُذكر فيه أن من صلاحيات الناظر فتح حساب للبنك، مما استدعى الرجوع للقاضي ليأذن بذلك بعد دورة إدارية أخذت كل تلك الفترة والتعطل. قد تبدو مثل هذه الأمور يسيرة لكنها قد تغيب عن غير صاحب الخبرة في كتابة الوثيقة الوقفيّة، كما يجب أن تُحدد نسبة الاستثمار من ريع الوقف، لوحئ، ومجالاته، وكم يوزع من الغلة، وكيف يوزع، مع وضع مرونة تتيح للنظارة ولإدارة التنفيذية التحرك في حدود المعقول دونما وجود حاجة لأخذ موافقة جهة ما أو استئذان مرجع آخر غير نظارة الوقف.

إن الصياغة الجيدة للوثيقة الوقفية تؤدي بالضرورة إلى عدد من الملامح المستقبلية لشكل أي وقف وذلك بعد توفيق الله عز وجل، ومن ذلك ضمان استمراره لأطول فترة ممكنة، وتوسعاه، وتنميته، وزيادة عدد المستفيدين منها وعدم تعطله، أو وصيوله لمرحلة الاندثار القسري، أو الاندثار الطوعي.

إن الوصول بالوثيقة الوقفية لتكون سياجًا حاميًا للوقف في وجاه عوادي الزمن، وفساد النظارة الفرديّة، والخلل في التشريعات - أحيانًا - يمكن أن يتمّ بالصياغة وسة 
وقد اجتهدت وصنفتها بحسب المجالات الرئيسة على النحو لموضح في الجدول رقم (1). جدول (1) التوزيع النوعي للمصارف الوقفية في الوثائق الوقفية

\begin{tabular}{|c|c|c|}
\hline تفصل المصارف في المجالات & $\%$ & المصرف \\
\hline أضياحي، وأوجاء بر عام، ودعم حلقات تحفيظ القرآن، وبناء المساجد، وإفطار & $\% 70.7$ & المجال الشرعي \\
\hline كفالة الأيتام، وإعانة زواج، ومساعدة الجمعيّّات وصناديق عائلية. & $\% 14.3$ & 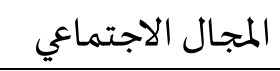 \\
\hline نشر العلم الشرعي والدعوة إلى الله، وبناء المدارس، ودعم البحوث والدراسـات. & $\% 9.3$ & 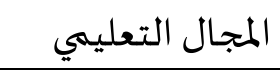 \\
\hline ويشمل حفر البئر وتوصيل الماء للمحتاجين بالصهاريج. & $\% 2.9$ & حفر الآبار \\
\hline تأمين أجهزة طبية، وغالبًا ما تكون لمراكز غسيل الكلى. & $\% 1.4$ & 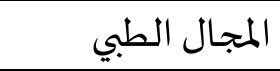 \\
\hline دعم القنوات الفضيائية والإعلام. & $\% 1$ & 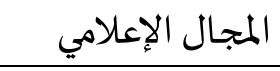 \\
\hline تقديم القروض الحسـنة، وسـداد ديون عن المعسرين. & $\% 0.4$ & المجال الاقتصادي \\
\hline & $\% 100$ & 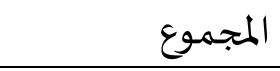 \\
\hline
\end{tabular}

المصيدر: من إعداد الباحث بناءً على بيانات "تقرير لجنة الأوقاف بغرفة الشرقية (2018م)، ص 60

\section{شكل (2) التوزيع النوعي لمصارف الأوقاف في المملكة العربية السعودية}

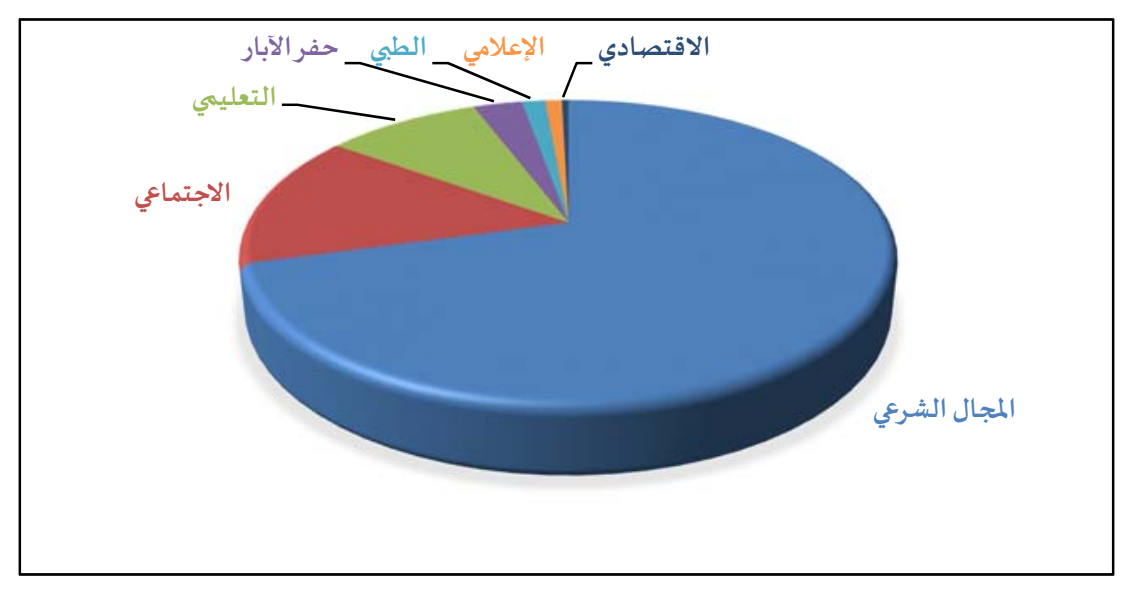

المصدر: من إعداد الباحث بناءً على معطيات الجدول (1)

إلى أوجه البر، ودعم حلقات تحفيظ القرآن، وبناء المساجد، وإفطار صائمين والمساعدة على أداء الحج والعمرة، وتجهيز الموتى، وهذا ما انتهى إليه التقرير الأولي للهيئة العامة

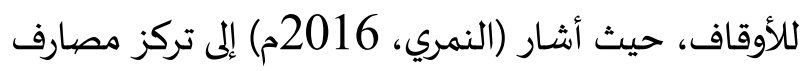

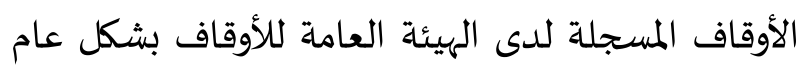

من الواضح غلبة المصيارف الشرعية على بقية المصارف التنموية الأخرى، حيث بلغت (70.7\%)، وتتمثل هذه المصارف في: ذبح أضاحي للمُوقِفِ أو والديه وهذا المصرف لهُف بمفرده (ذبح الأضاحي) استحوذ على (19.5\%) من جملة

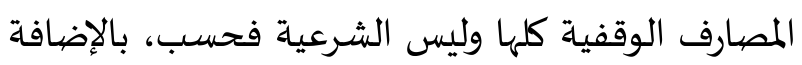


وتنمية الوقف بحسب وجهة نظر الناظر، فغلتها تكفي كل

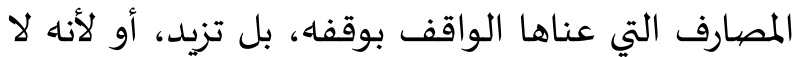
يوجد نص صريح في الوثيقة الوقفيّة يسمح بالاستثمار من فائض الغلة، وهذا ما يُشير له (الزيد، 1420ه، جيك، ص1483) وقد كان من كبار المسؤولين عن الأوقاف في المملكة العربية السعودية بقوله: "إن بعض الأوقاف يزيد

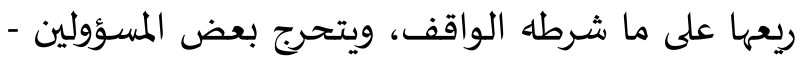
النظار- في التصرف بفائض الأوقاف وصرفه في غير ما

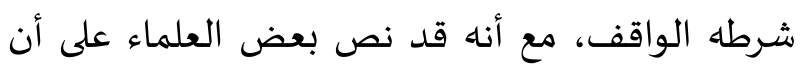
فائض الوقف يصرف في المصالح التي هي نظير مصالحها." إن الغالب الأعم في الوثائق الوقفيّة في المملكة أنها لا

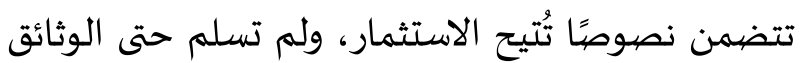
الحديثة جدًا، والمقصود بها الوثائق التي كتبت خلال عام (1437هـ/2016م)، حيث يذكر تقرير لجنة الأوقاف بغرفة الشرقية (2018م) أن (36.9\%) من الأوقاف المسجلة في العام (1437هـ) لم تُخصص جزءًا من غَلَّةِّة الوقف للاستثمار، وهذا ما يحرم الوقف من زيادة أعيانه، وبالتالي زيادة عدد المستفيدين من الغلة، وحرمان الواقف

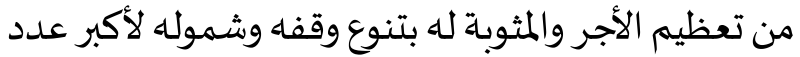

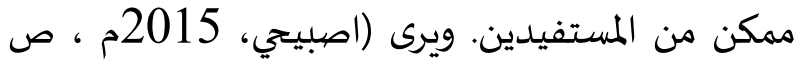

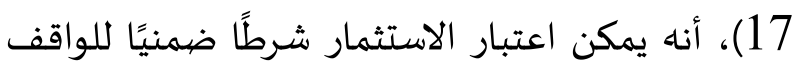
ولو لم يذكره، لأن قصد الواقف أن ينفع الموقوف عليه،

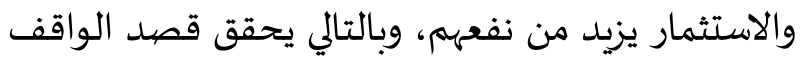

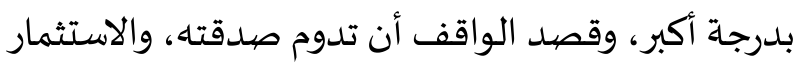
من أبواب دوامها، إلا إذا كان الواقف وضيع شرطًا صريحًا بعدم الاستثمار، وقسمة الغلة كليًا على الموقوف عليهم فحينئذ يوفى بشرطه. بل يرى (الصقيّه، 1434 14ه، ص118) أكثر من ذلك وهو: أنه حتى لو اشترط الواقف في الوثيقة الوقفية عدم الاستثمار من غلة الوقف، فلا
على الاحتياجات الدينية والاجتماعية وعدم شمولها لقطاعات عامة أخرى مما يحد من تأثير الوقف على التنمية الاجتماعية والاقتصادياة، وعدم استهداف البرامج لأهم الاحتياجات وتركزها فقط على المساعدات الخيريّة. كما تتصف الوثائق الوقفية بغيابها عن تحقيق التوازن بين المنفعة الاقتصادية والمنفعة الاجتماعية للوقف، وأحيانًا يسمى العائد الاقتصادي والعائد الاجتماعي، ويقصد بذلك إلى أين تميل كفة الوقف أهي إلى تنميته وتثميره، أم إلى الصرف من الغلة للمستفيدين فقط. وهي معادلة حرجة نتائج غلبة إحداها على الأخرى وخيمة. لأن التركيز على المنفعة الاقتصادية أي تزايد دخله ورصيده دون صرف اجتماعي يتناسب مع ريع الوقف يؤدي إلى خروج الوقف عن أساسـ، وفلسفته وهو فيضان خيراته على المجتمع وعلى الفئات المراد لها أن تنتفع من الوقف، كما أن رجحان المنفعة الاجتماعية في تلك المعادلة يعني زيادة حجم الاستهلاك والإهلاك لأصل الوقف حتى وإن كانت تعني زيادة الرفاه الاجتماعي ظاهرًا ومؤقتًا، إلا أنها تعمل بالضرورة على ضعف المنفعة الاقتصادية وفي ذلك خطر

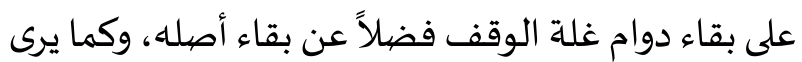
(بن بيا،، 1426هـ، صل16) أن تحقيق "هذه المعادلة بين

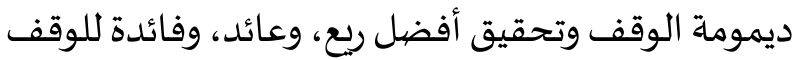
يجب أن توضيع نصب أعين الأطراف المسؤولة عن شئون المون

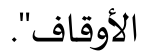
كما يجب عدم تركها راجعة لتخمينات الواقف التي غالبا ما تكون قائمة على غير مستند علمي صحيح، بل اجتهادات محضية وشواهد الحال تحكي ذلك بكل تفصيل، فكم من الأوقاف كانت غلتها كبيرة جدًا، ومصارفها محدودة جدًا (نوعًا وكمًا)، مما أوجد إشكالاً في تراكم الأرصدة دون وجود استثمارات للمتبقي من الغلة، إما بسبب عدم وجود الحاجة للزيادة في الأعيان الوقفية 
نظارة أو إدارة مؤسسية يفوق بمراحل النظر الفردي من حيث إصابة الرأي، وبعد النظر وشمول الرؤية وتقدير المالآت، وبخاصة حينما يكون المجلس من تخصصيات

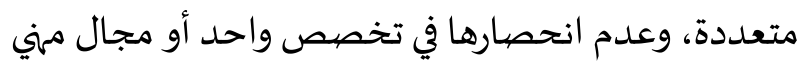
واحد، "فكوننا نكل الأوقاف إلى أفراد، أو إلى القضياة، فهذا وادها مُضعف للوقف، مُوقف لمصالحه، لارتباطه بأشخاص، يزول بزوالهم، ويضعف بضعفهم، بخلاف المؤسسات القائمة على نُظم كاملة لا تتغير وتتبدل بتبدل الأفراد .. ثُم إن العصر الذي نعيش فيا عصر المؤسسات، فما اتصل بها دام وازدهر، وما انفصل عنها زال وانقطع" (النجران،

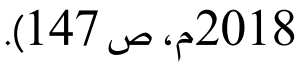
كما يؤكد ذلك (الفوزان، 1434هـ، ص159) برأي جازم من واقع خبرته وتعامله مع الأوقاف وقضاياها، بقوله: "لا شيء أنفع في النظارة على الأوقاف - لكي تحفظ أعياه وأعيانها،

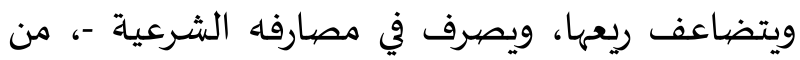
تعيين مجلس نظارة مكون من ثلاثة أشخاص وأكثر بحيث يكون الرأي جماعيًا، ورأي الجماعة أكثر سدادًا من رأي مناي الفرد، .. وهذه نصيحة لكل من لدياه وقف خيريّ عام أو خاص، وهي نتيجة خبرة ومعاناة في هذا المجال". إن مما لا شك فيه أن من الأسباب التي أضعفت

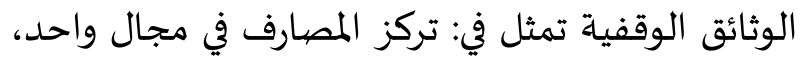

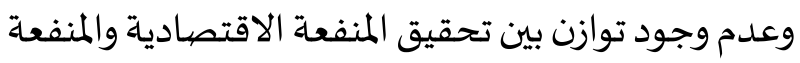
الاجتماعية للوقف، وضعف تثمير الوقف لتعظيم منفعته، وغلبة النظارة الفرديّة على الأوقاف بما يكتنف ذلك من قصور إداري واستثماري ونفعًا، راجعًا بدرجة

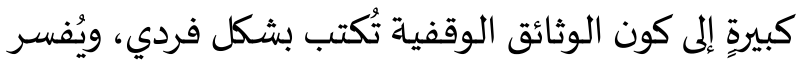

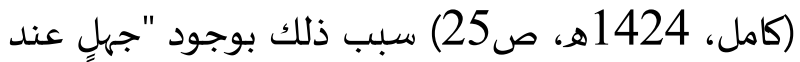
وضع شروط الواقف من البداية حيث يكون الواقف بخبرته الفردية تحت ضغط الخوف من ظروف أحاطت باه

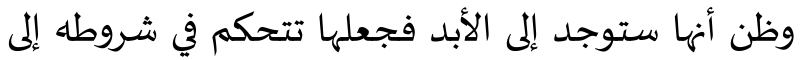

يُلتفت إلى هذا الشرط وبالتالي يحق للناظر أن يستثمر من غلة الوقف ما لم يكن هذا الاشتراط من الواقف درءًا لمفسـدة راجحة. وعلى كل حال فإن هذا الرأي لا يُعمل باه في محاكم المملكة، لوجود "تشدد" في الالتزام بشروط

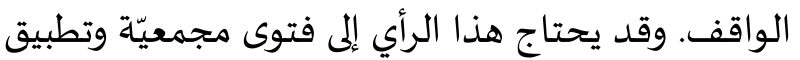
عمليّ على أرض الواقع مطمئن للحفاظ على الوقف، حتى يُكتب له الانتشار، كما حصل في كثير من النوازل الوقفية

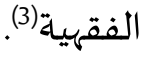

ومما يؤخذ حتى على الأوقاف التي وجد أن الاستثمار فيها مُتاح أنها تنحى إلى الاستثمار في مجالات محدوددة، فهي تتجه إلى العقار بالدرجة الأولى، حيث بلغت النسبة في

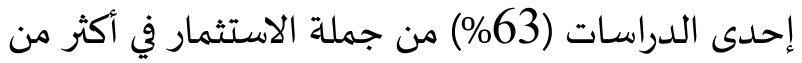
عشرة أوقاف من كبرى الأوقاف في المملكة العربية السعودية، يليها الاستثمار في الأسهم المحلية بنسبة

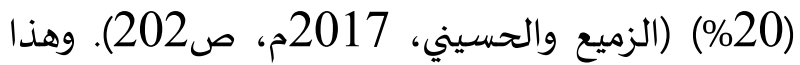
التوجه الاستثماري المُنحصر في العقار غالبًا عائد إلى غلبة النظارة الفردية التي سنتحدث عنها في الفقرة الآتية. أما في شكل النظارة فقد أظهر تقرير لجنة الأوقاف بغرفة الشرقية (2018م) أن النظارة الفرديّة تسيطر على ما نسبته (72.9\%) من جملة الأوقاف، وهذه المرحلة من

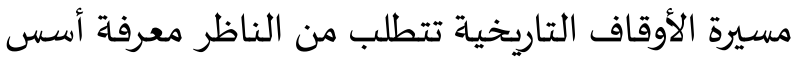
العمليات الإدارية، وهي: التخطيط، والتنظيم، والتوجياه، والرقابة، وتختلف درجة هذه المعرفة باختلاف حجم الوقف، وهذه المتطلبات تؤكد وجود (نظارة جماعيّة)،

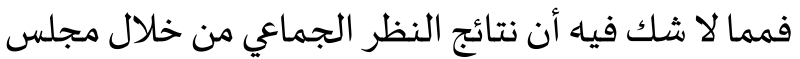

(3) سبق لمنتـدى قضيايا الوقف الفقهية الرابع الذي نظمتـه الأمانة العامة

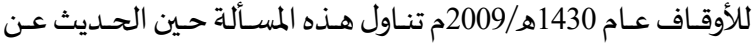

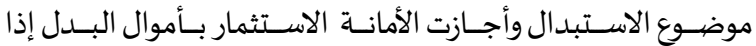

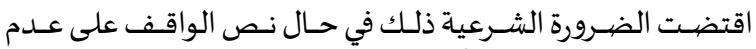

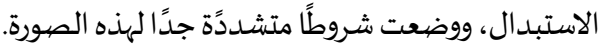


مجلس نظارة يرأسـاء الواقف نفسـه طالما كان قادرًا، ويضم المجلس أحد عشر عضوًا، خمسة منهم من أبناء الواقف وأبناء أبنائه، وستة من غير ذرية الواقف ومن غير عصبتها، ومن غير ذوي رحمه أو من تربطهم باه مصاهرة، وثلاثة من

$$
\text { هؤلاء الستاة يكونوا من أهل العلم الشريعي. }
$$

وقد وضعت الوثيقة فقرة تفصيليّة تتيح لمجلس النظارة أن يُنهي الوقف بما لا يزيد عن ثلث صافي الغلة،

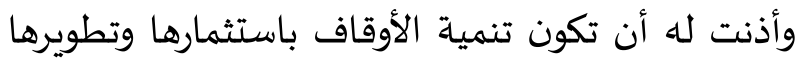
وتشغيلها، أو بإضافة أصهول جديدة، أو بزيادة نصييها في

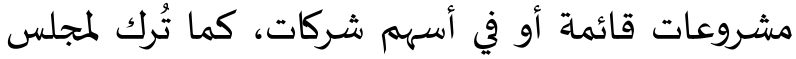
النظارة أن ينقص عن الثلث بما يراه محققًا للمصلحة. وليس هذا فحسب، بل أذن للمجلس أن يُكون احتياطي ئنس ئنس

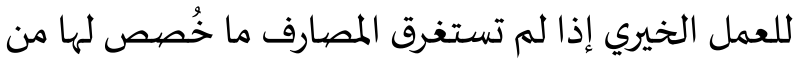
الغلة أو تعذر الصرف عليها، ويُستثمر ذلك الاحتياط بشكل آمن قصير المدى، وإذا بلغ الاحتياط نسبة معينة حددها الواقف، جاز استثمار الفائض بشكل دائم طويل

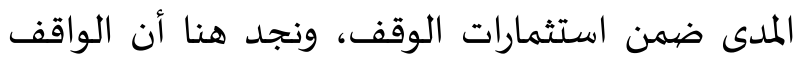
وضع لكل احتمال تصرف يتخذه المجلس ولم يترك المجلس في حرج فقهي، أو نظامي أو قانوني، وهذا يتكرر في معظم

$$
\text { فقرات الوثيقة الوقفيّة. }
$$

وبعد ذلك سردت الوثيقة مصارف غلة الوقف وبدأها بإصلاح ما خرب من الأوقاف وتجديد ما يحتاج إلى تجديد

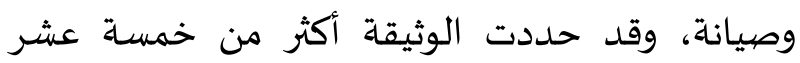

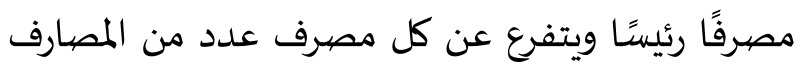
الفرعياة، ومن ذلك على سبيل المثال هذا المصرف: (تعليم القرآن الكريم وطباعتاه والعناية باه وتوزيعه، ونشره بجميع الوسائل، ودعم حلقاته ومدارساه، وتشجيع حافظيه

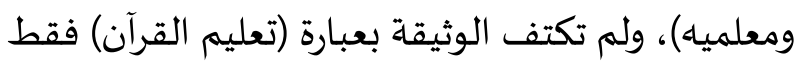

http://saaid.net/book/open.php?cat=\&book=15023
الحد أن بعضهم قد كتب مثلا (لعن الله من يغير في هذا

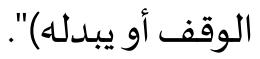
إن هذه الرؤية الفرديّة في كتابة الوثيقة الوقفية، والتصرف في إدارة الوقف من خلال ناظر واحد، يمثل

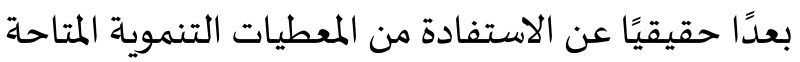

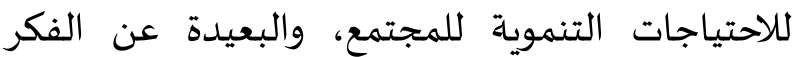
التنموي الجمعي، وتجعل الإشكال يستمر بطبيعة الحال

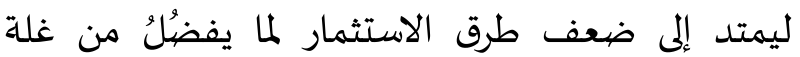
الوقف، وأدوات ذلك الاستثمار، وكذلك تطويره بتطور

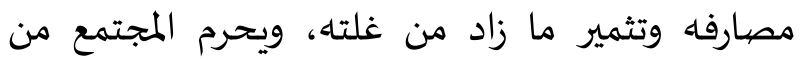

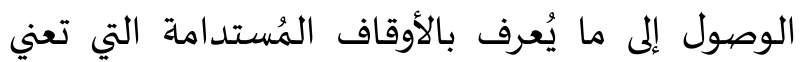
تحقيق المنفعة الاقتصادية دون الإضرار بالمنفعة الاجتماعية للوقف.

\section{5- نموذج معاصر للوثيقة الوقفية المنشودة} لعل من المناسب في هذا السياق الإشارة إلى نموذج عملي معاصر لوثيقة وقفيّة بُذل في صياغتها، وتحسينها، وتطويرها جهدٌ كبيرّ، حيث استمر التطوير عدة سنوات لأن الواقف (الشيخ/ سليمان بن عبدالعزيز الراجي) لازال على قيد الحياة وقد اشترط أن يكون صك الوقفيّة قابلاً للتطوير مع ما يستجد من ظروف وتطورات مادام على قيد

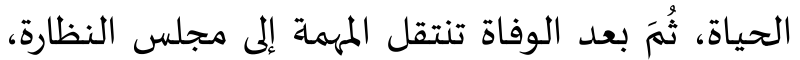
وهذا الوقف تصل قيمتاه إلى قرابة (60) مليار ريال بما يعادل (16) مليار دولار تقريبًا، ويتكون الوقف من عدد من الشركات الزراعية، والصناعياة، والحيوانياة، والعقارات والأسهه، وفي هذه الوثيقة الوقفيّة مادة علميّة ثريّة في

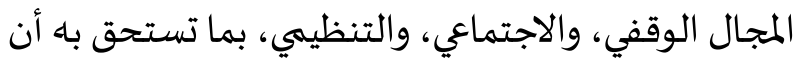

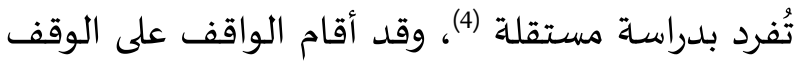

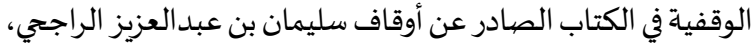


ذلك كل ثلاث سنوات"(أوقاف سليمان بن عبدالعزيز

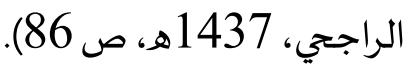
ولتحقيق مزيدًا من الضبط أنشأ الواقف مؤسسة خيريّة خاصة في عام (1421هـ/2001م) باسم (مؤسسة سليمان بن عبدالعزيز الراجي الخيريّة) مسجلة رسميًا في وزارة العمل والتنمية الاجتماعية، ومستقلة إداريًا عن النيات الوقف وبمجلس إدارة مستقل، فأصبحت بمثابة الذراع الرئيسي لصرف الجزء الأكبر من غلة الأوقاف (أوقاف

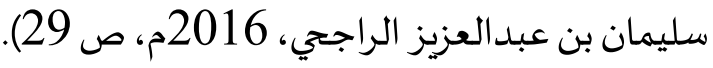

\section{6- نحوتحقيق دورأكبرللوقف في المملكة العربية السعودية}

منذ أكثر من عشر سنوات توقع العديد من الباحثين أن تكون المملكة العربية السعودية الدولة الأولى بين الدول

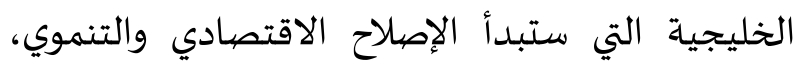

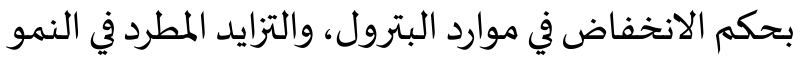
السكاني، مما سيجعل من الصعب الاستمرار في تقديم نفس مستوى الرعاية الشاملة للجميع وبلا توقف، وهذا

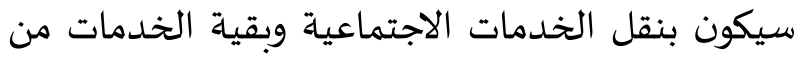
الكاهل الحكومي إلى الكاهل المدني، وتتفرغ الحكومة

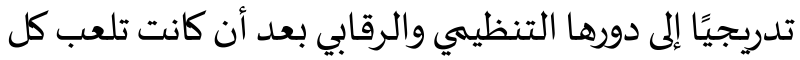

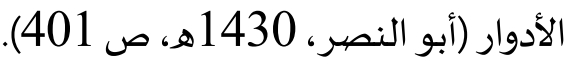

وقد كان ذلك بالفعل، ففي العام المنصرم بدأت المملكة العربية السعودية في تطبيق برامج الإصلاح

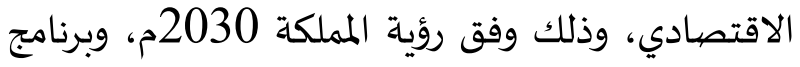
التحول الوطني (2020م) بنسخته الأولى، والثانية، فقد وفد

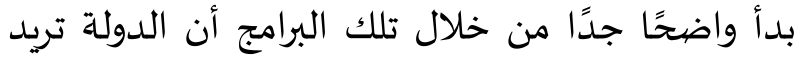
التخفيف من تبعات برامج الرعاية الاجتماعية، والصحية،

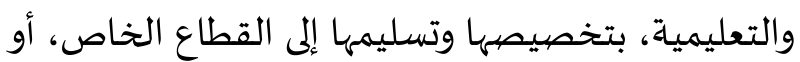

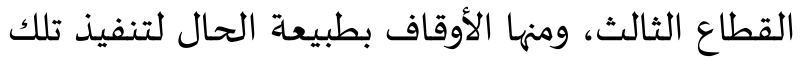

كما في بعض الوثائق الوقفيّة، وبالتالي قد يتحرج مجلس النظارة من الصرف على الأعمال الأخرى المساندة لتعليم

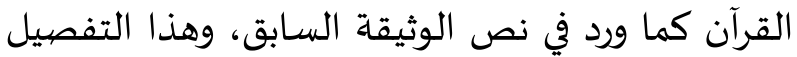
يُمكن مجلس النظارة من التوسع في تفريعات المصرف بحسب الحاجة في كل وقت أو مكان. وهكذا يتكرر هذا الأسلوب في كل مجال من المجالات فيذكر المصرف الرئيسي وتفريعاته تفصيلاً ويُختم بما يُتيح التوسع في المجال ذاتها وبعد ذلك تحدثت الوثيقة عن مجلس النظارة وكيفية تكوينه، ومهامه، وضوابط عمله، واختصاصاته، ومكافآت أعضائه، وكيفية اتخاذ القرار فيه في تفصيل دقيق، وفي وفيانيان فقرة مستقلة تتحدث الوثيقة عن تعارض المصالح بالنسبة لأعضاء مجلس النظارة، في سبع فقرات تفصيلية. كما تناولت الوثيقة آلية التعامل مع الواقف نفسها، فيما لو ظهرت عليه علامات الضعف المؤثرة في أهليته، وكيفية انتقال رئاسة مجلس النظارة منه لأحد أعضاء المجلس. وقد حاولت الوثيقة وضع معادلة للتوازن بين المنفعة الاجتماعية والمنفعة الاقتصادية، حيث ورد ضمن مهام مجلس النظارة الآتي: "على مجلس النظارة التأكد من قدرة

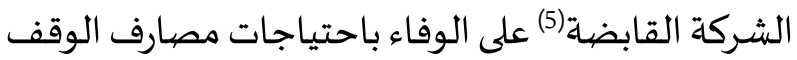
على المدى القصير والبعيد وبشكل منتظم والتاكد كذلك من أن استثمارات الشركة القابضية تحقق توازنًا بين العائد النقدي والنمو بالنسب المقبولة في السوق بحسب الزمان وأن النمو في أصول الشركة القابضة التي تملكها بشكل

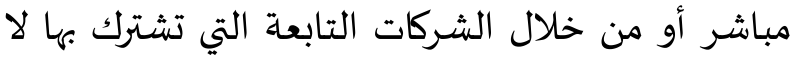
يغلب على معدل الاتفاق في العمل الخيري، ويتمّ تقييم

(5) أسس الواقف في عام 1432هـ (شركة قابضة للأوقاف) سُجل باسمها

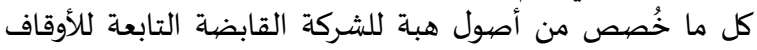

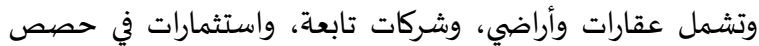

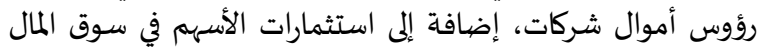

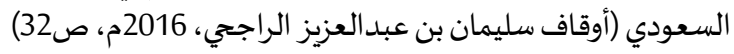


7- - 1 - 1طوة عملية إن المتأمل في الساحة الوقفية عامة في وقتنا الحاضر، وكما تظهره كثيرّ من الدراسات وشواهد الحال لا يخفى عليه عدم قدرة كثير من الواقفين - كأفراد - على التحديد بدقة لمواطن الاحتياج للمجتمع بشكل عام، أو انحصيار الواقف في واقعه الجغرافي والزماني المحدود، ولا يمكن تغطية مثل هذا الخلل إلا من خلال فرق عمل ذات نظرة شمولية ومتحررة من الواقع الجغرافي المكاني، والزماني

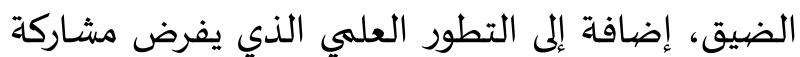
مختلف التخصصات لتحديد هذه الاحتياجات بناءً على أسس علمية تتواكب والتقدم العلمي الذي هيأ رصيدًا وافرًا من الإحصاءات مما يجعل الكثير من التوقعات تتحقق بالفعل مع مرور الزمن فحاجة الواقفين للإرشاد في هذا المجال قائمة ومتجددة بتطور المجتمع وتنوع احتياجاته، ومن هنا فلا بد أن تضع الدولة خطة اقتصادية تراعي حاجات المجتمع، وأن تستقطب الخبراء بمختلف تخصصاتهم لذلك، حتى إذا تمّ إعداد هذه الخطة، - ومن ذلك الخطط الخمسيّة للدولة -، عُرضت إنه هذه المشاريع على أثرياء الأمة بتكلفتها والمردود المرجو منها من خلال محاضن وقفية ترعى الصياغات الوقفية

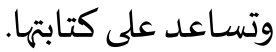

ويمكن أن يكون هذا من خلال مراكز علمية موثوقة تستند في دراساتها وتوقعاتها على الإحصاءات، والمسوح الميدانية، والدراسات الاستشرافية للمستقبل من خلال التعرف على الواقع وإمكاناته، والمستقبل وحاجاته، كما ينبغي توسعة النظر ومداه إلى الآلية المقترحة لتحقيق النفع الأكبر من الوقف تكون من خلال كتابة الوثيقة الوقفيّة بشكل مُحكم متضيمنه كيفية إدارة الوقف وشكل النظارة مع طرح الأوجاء الجديدة من المصارف التي يحتاجها
البرامج، وإدارتها، وتطويرها. ولقد حرصت رؤية 2030م على تعظيم دور الأوقاف باعتباره الممول الأكبر والمُستدام لقطاع العمل الأهلي، والخيّري، وغير الربحي في المملكاة، حيث ألزمت الرؤية نفسها في معرض الحديث عن تطوير

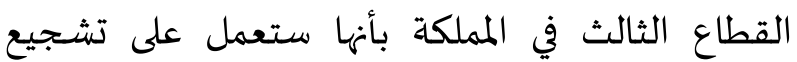
الأوقاف لتمكين هذا القطاع من الحصيول على مصيادر تمويل مستدامة، ومراجعة الأنظمة واللوائح المتعلقة بذلك. وأنها ستعمل على تعظيم الأثر الاجتماعي للقطاع غير الربحي، من خلال إسهام نظام الجمعيات والمؤسسات الأهليـة ونظام الهيئة العامة للأوقاف في تمكين القطاع غير الربحي من التحول نحو المؤسسية. (رؤية المملكة العربية السعودية 2030، 2016م، ص ص: 69-73) كما ورد في برنامج التحول الوطني (2020م) في نسخته الثانية الإشارة إلى تحقيق التكامل بين القطاع غير الربحي، والهيئة العامة للأوقاف، لزيادة أثر القطاع غير الربحي اقتصاديًا. ولا شك أن من الخطوات العمليّة لتحقيق هذا التكامل تكليف وزير العمل والتنمية الاجتماعية رئيسًا لمجلس إدارة الهيئة العامة للأوقاف، فقد يكون هذا من مرامي دمج القطاعين (التنمية الاجتماعية) و (العمل) في وزارة واحدة باسم وزارة العمل والتنمية الاجتماعية، ووضع المسؤول الأول عن التنمية الاجتماعية هو المسؤول الأول عن الأوقاف في المملكة، بحيث تسهئل عملية التنسيق بين القطاعين، (السدحان، 2018م). إن كل هذه المحفزات المرحليّة، وإقبال الدولة لتعظيم دور الوقف يؤكد ضرورة الارتقاء بمنظومة الوقف الذاتية

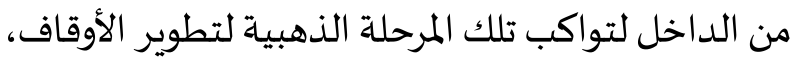
تزامنا وتحقيقًا لتعهد الدولة بتنظيم ما يخصها بشأن الأوقاف، من حيث التنظيم، والتشريع، والتمكين، والتطوير المؤسسي. 
وهناك عدد من الاشتراطات الضرورية لنجاح مثل هذا المركز أو المراكز التي سوف تتخصص من الاتراط في مساعدة الواقفين على صياغة وثائقهم الوقفيّة، ومن ذلك على سبيل المثال: 1) أن يتمتع ذلك المركز باستقلالية إدارية ومالية،

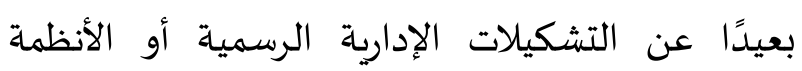

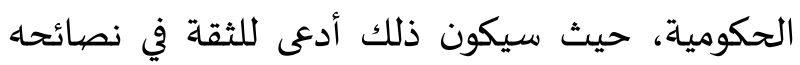

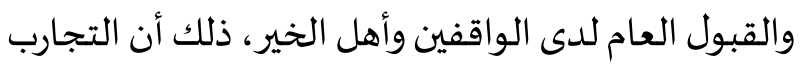

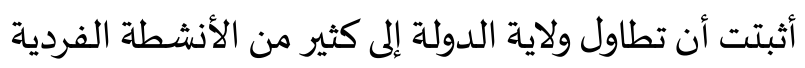

المجتمع بشكل أكبر سواء كانت من الاحتياجات التي تعمل

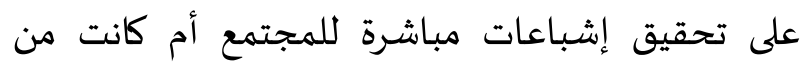
الاحتياجات التي تكون منفعتها بشكل غير مباشر وعلى آماد طويلة، وكل ذلك يمكن تحقيقه من خلال وجود مركز أو أو

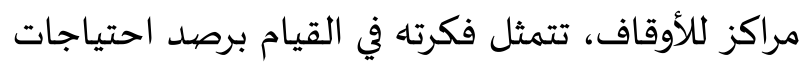
المجتمع مستفيدة لتحقيق ذلك من الدراسات المسحية وخطط التنمية السنوية أو الخمسية، وتسويق هذه الاحتياجات - باعتبارها منتجا كأي منتج تجاري - على الى الفيان الواقفين ويكون من باب الإششاد لهم وليس فيه أي بعد الهدا

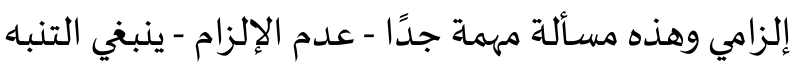

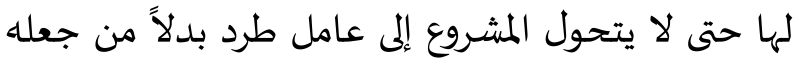
عامل جذب للأوقاف الجديدة في نوعها وكميتها، فلقد

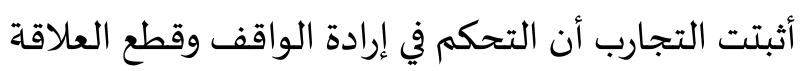

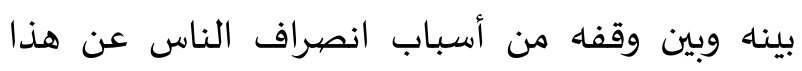

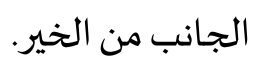

ويتوقع من هذا المركز أن يكون ذا أفق واسع في اقتراح شكل النظارة، وآليات عملها وتراتيها الإدارية، وحوكمتها،

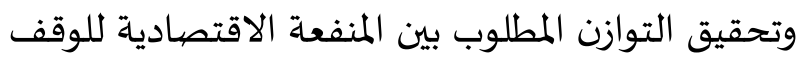
والمنفعة الاجتماعية له، أو ما يُسمى مقياس (العائد الوقفي) ويقصد به المواءمة بين متطلبات حُسن استثمار أعيان الوقف وبين حاجات التنمية الاجتماعية والتنمية الشاملة، وهذا سيؤدي إلى ظهور صيغ جديدة للوقفيّات

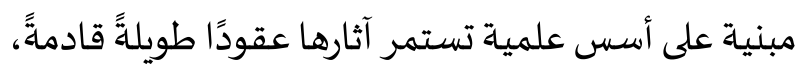

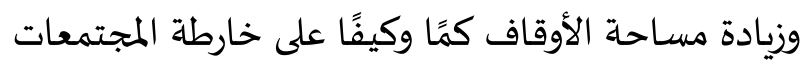

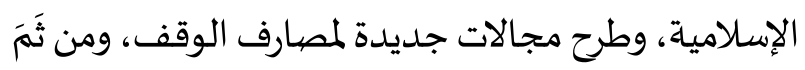
سد الكثير من احتياجات المجتمع مما عجزت الحكومات

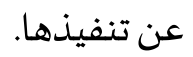


4) حضور الدولة في هذا المجال يجب ألا يتجاوز التنظيم العام والترخيص وفق اشتراطات أساسية، ومن

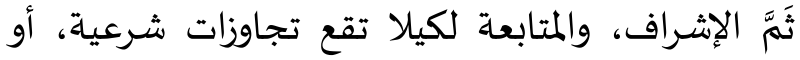
قانونية، وتجاوز الدولة لهذا المستوى الإداري في منظومة عمل هذه المكاتب يضرُ بمستقبل المكاتب ومصداقيتها، ويُضعف دورها التطويري المنتظر.

وبحسب دراسة نشرتها (لجنة الأوقاف بغرفة الشرقية 1436هـ) تبين أن في المملكة العربية السعودية قرابة خمسة عشر مكتبًا تقوم بصياغة الصكوك والوثائق الوقفية، ولا شك أن هذه ظاهرة إيجابية تساعد في تسريع تفعيل الدور التنموي للأوقاف، والاستفادة من الأوقاف الجديدة لتوجيهها نحو المسار التنموي الذي تتطلبه المرحلة وينتظره المجتمع، لتعود المؤسسة الوقفية قائدًا

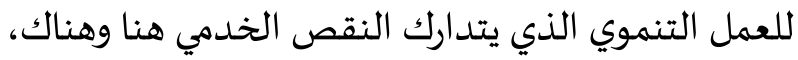
ويسد الثغرات الناتجة عن تضاؤل دور دولة الرفاهية،

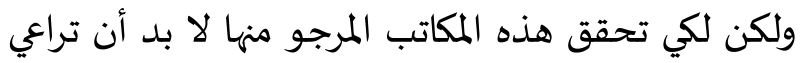
النقاط الأربعة الآنفة الذكر، من حيث استيعاب فريق صياغة الوثائق لكل التخصصات الأساسية لاستشراف الاف

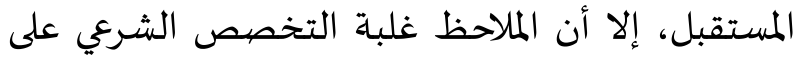

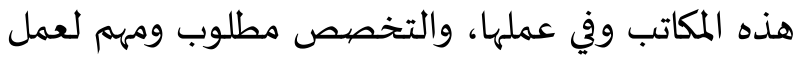
هذه المكاتب، بل أساس، ولكن غياب التخصصيات الأخرى يُضر بالصياغة المتقنة للوثيقة الوقفية.

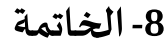
إن مما يؤكد النظرة التفاؤلية لهذا المشروع الحضاري (الوقف) وإعادة دوره التنموي الفاعل في المجتمعات المسلمة حاضرًا ومستقبلاً ما يمتلكه هذا المشروع من
أدى إلى وجود قطيعة سياسية واجتماعية وفكرية بين الدولة والأفراد، ودفع بالإفراد إلى النأي بأنفسهم عن الناديان

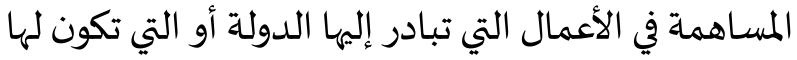
ولاية علهها أو وجود فهها. (النجار، 1427هـ، ص175). 2) أن يكون لدى تلك المكاتب التنوع العلمي في التخصصات، التي تساعد على إعداد الوثيقة الوقفيّة

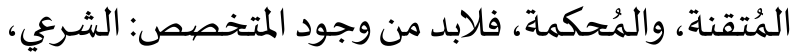

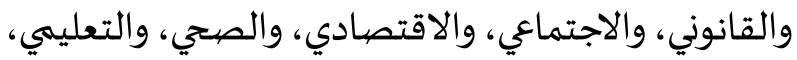
والإحصائي، ومن لديه استشراف للمستقبل، بحيث تكون صياغة الوثيقة الوقفيّة صياغة جماعية ذات بعد شمولي استشرافي للمستقبل، وصياغة قانونية محكمة تتضاءل فهيا احتمالات التفسير لمحتواها، ويقل فيها تفاوت الإفهام أو التأويلات لبنودها، بالإضافة إلى ضبط المصارف

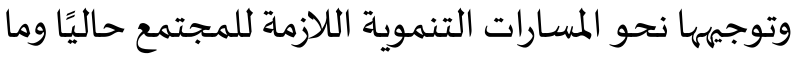
يتوقع خلال عقود قادمة، وفق تدرج الأولويات المعروف:

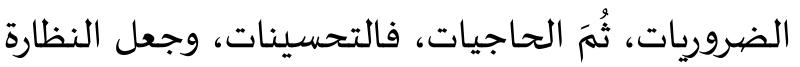

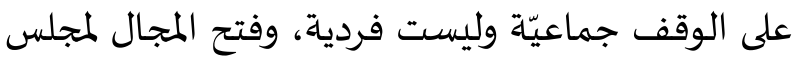
النظارة لكي يستثمر وينهي الوقف، ليعظم المصلحة للمستفيدين ويحقق تعظيم الأجر للواقف، ويُفوض في موضوع الصيانة أو الاستبدال بحسب المصلحة التي يراها

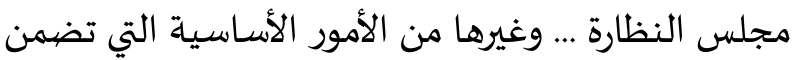
إطالة عمر الوقف وزيادة منفعته.

3) ضرورة ألا تشارك تلك المكاتب الاستشارية، أو أحد منسوبها أو مستشاريها في مجالس النظارة المقترحة لأي وقف يقوم المكتب بصياغة وثيقته الوقفية، وذلك لضمان سياسة عدم وجود تعارض للمصالح، وبالتالي تفقد هذه وادها المكاتب مصداقيتها في السوق الوقفية، ويضمحل أثرها ويتناقص دورها، بسبب عزوف الواقفين عنها. 
السمات التي يمتاز بها الوقف يجعل المستقبل مُنصبغًا بنظرة تفاؤلية نحو إعادة الدور المعتبر والمكانة اللائقة بهاه في الماني مسيرة الحضارة الإسلامية، ولكن هذه العودة مشروطة بإعادة النظر في كيفية تعامل الواقفين مع أوقافهم،

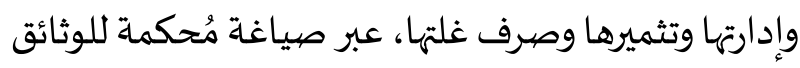
الوقفية، تُضبط فيه المنظومة الوقفية بدءًا من الإيقاف،

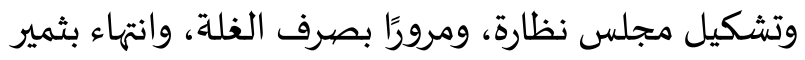
الوقف وزيادته، ويكون هذا عبر مكاتب مستقلة ذات خبرة: شرعية، وإدارية، وقانونية، واجتماعية، واقتصادية، واستشرافية للمستقبل. وهذه الخطوة التطويرية المطلوبة

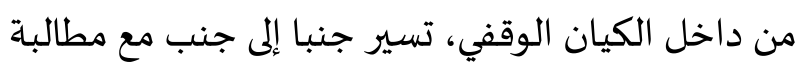
الدول بالتشريعات الحامية للوقف، والتنظيمات المطمئنة للواقفين لكي نضمن نجاحه بإذن الله.
مرتكزات أساسية، ومن ذلك: التعاطف الشعبي، وإقبال عامة المسلمين عليه بمختلف مستوياتهم العلمية والاقتصادية وبمختلف صوره والحرص على تقديم ما

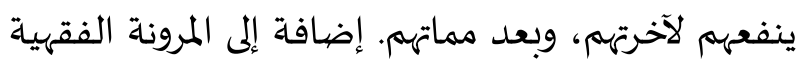

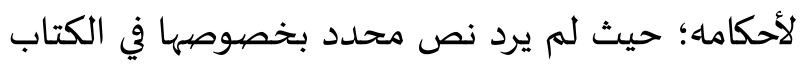
ولا في السنة، فالذي ورد حكم إجمالي عام، أما تفاصيل أحكام الوقف المقررة في الفقه الإسلاهي فهي اجتهادية. كما يمتلك الوقف المؤهلات الكاملة والصيغ الشرعية

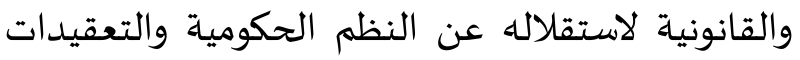
الإدارية، ذلك أن الوقف بمجرد إنشائه تصبح له شخصية النالية

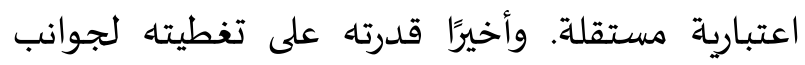

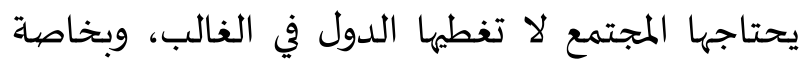

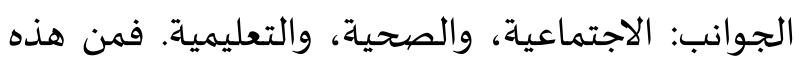




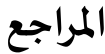

السدحان، عبدالله (2018م) العمل الخحيري المُنظم في المملكة

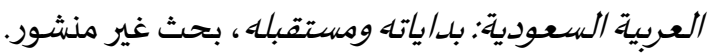

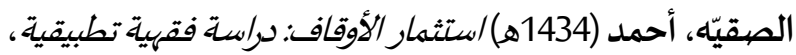
ط1، الدمام، المملكة العربية السعودياة، دار ابن الجوزي.

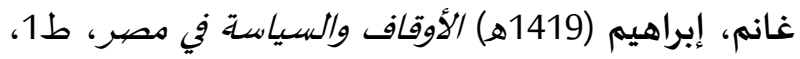

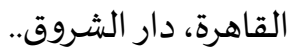

الفوزان، عبدالعزيز (1434هـ) مسؤولية الدولة في حماية الأوقاف، مجلة العدل، العدد 58، الرياض، المملكة العربية

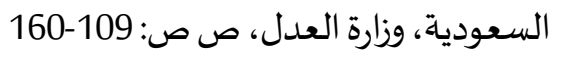
كامل، عبدالعزيز (1424هـ)، خواطرفي العمران، ط1، هوده (د.ن.).

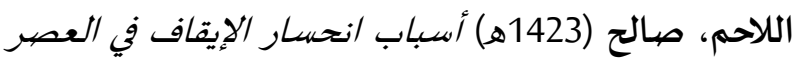

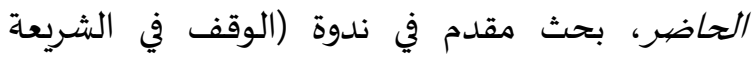

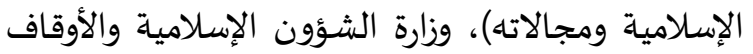

والدعوة والإرشاد، الرياض، المملكة العربية السعودياة. لجنة الأوقاف بغرفة الشرقية (1436هـ)، الشراكة في مجال الأوقاف، ط1، الدمام، المملكة العبية السعودية، الغرفة التجارية الصناعية بالمنطقة الشرقية. لجنة الأوقاف بغرفة الشرقية (2018م)، تقرير اقتصاديات الأوقاف، ط1، الدمام، المملكة العربية السعودية، الغرفة التجارية الصناعية بالمنطقة الشرقية. مسلم، مسلم (1421هـ) صحيح مسلم، ط1 بـ، الرياض، المملكة العربية السعودية، دار السلام. النجار، عبدالله (1427هـ) ولاية الدولة على الوقف: المشكلات والحلول، بحث مقدم إلى (المؤتمر الثاني للأوقاف بالمملكة

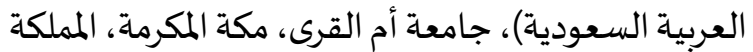

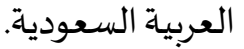
النجران، سليمان (2018م) الوقف الندري: مقاصلده، ووسائل إصلاحه، ط1، الرياض، المملكة العربية السعودية، مركز

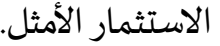
النمري، عبدالله (2016م) نظام الهيئة العامة للأوقاف ودورها

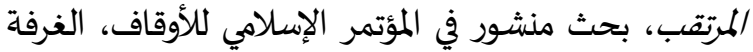
التجارية بمكة المكرمة، مكة المكرمة، المملكة العربية السعودية.
المراجع العربية أبو النصر، محمد (1431هـ) اغتراب الرعاية الاجتماعية في مجتمع الرفاه، ط1، القاهرة، المكتب الجامعي الحديث. اصبيجي، عبدالرزاق (2015م) إدارة واستثمار موارد الأوقاف. الإشكالات والتحديات، مجلة أوقاف، الكويت، الأمانة

العامة للأوقاف، العدد 29، ص ص: 13-35.

أوقاف سليمان بن عبدالعزيز الراجتي (2016م) الشيخ

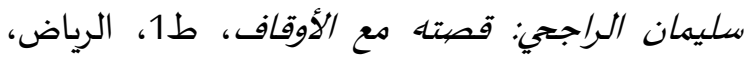
المملكة العبية السعودية، أوقاف سليمان الراجيتي.

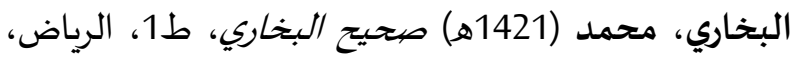
المملكة العربية السعودياة، دار السلام.

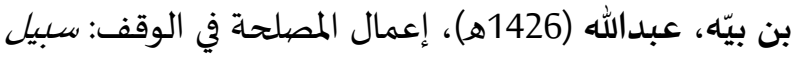

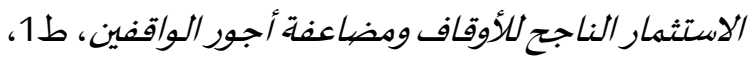

$$
\text { بيروت، لبنان، مؤسسة الريان. }
$$

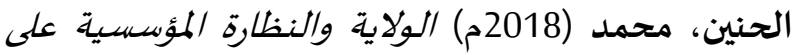
الوقف، ط1، الرياض، المملكة العربية السعودية،

$$
\text { مؤسسة ساعي لتطوير الأوقاف. }
$$

الحوراني، ياسر (2010م) المشكلات المؤسسية للوقف في التجبِة الإسلامية التاريخية، بحث مقدم إلى الندوة الدولية الأولى لمجلة أوقاف، الكويت الأمانة العامة للأوقاف.

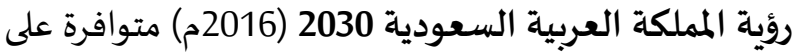
http://vision2030.gov.sa/ar:الرابط الزرقاء، مصطفى (1419ه) أحكام الأوقاف، ط1، عمان، دار عمار. الزميع، تركي. الحسيني، عامر (2017م)، الأوقاف في المملكة

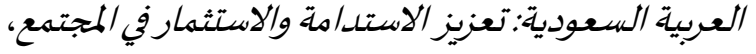
ط1، الرياض، المملكة العربية السعودية، مركز البحوث والتواصل المعرفي. الزيد، عبدالله (1420هـ) الواقع المعاصر للأوقاف في المملكة العبية السعودية وسبل تطويرها، بحث منشور في ندوة

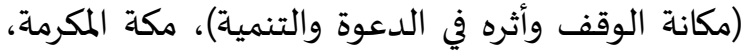
المملكة العربية السعودية، وزارة الشؤون الإسلامية والأوقاف والدعوة والإرشاد، مكة المكرمة. 


\section{Translation of Arabic References}

Abu al-Nasr, Muhammad. (1431H). Ightiraab al-Ri'ayah al-Ijtima'iyyah fi Mujama' al-Rifah (Exploitation of Social Welfare in Welfare Societies). Cairo, Egypt: alMaktab al-Jami'i al-Hadith.

Asbihi, Abdul Razzaq. (2015). Idarah wa Istithmaar Mawarid al-Awqaf: al-Ishkalat wa al-Tahaddiyyat (Management and Investment of Endowments' Resources: Problems and Challenges). Awqaf Journal, Kuwait, The General Secretariat of Endowments, 29, pp. 13-35.

Awqaf Sulaiman bin Abdul Aziz al-Rajhi. (2016). alShaikh Sulaiman al-Rajhi: Qissatuhu Ma'a al-Awqaf (Shaikh Sulaiman al-Rajhi's Story with Endowments). Riyadh, KSA: Author.

al-Bukhari, Muhammad bin Isma'il (1421H). Sahih alBukhari (The Authentic Narrations by al-Bukhari). Riyadh, KSA: Darussalam.

Bin Bayyah, Abdullah. (1426H). I'maal al-Maslahah fi al-Waqf: Sabeel al-Istithmaar al-Najih li al-Awqaf wa Mudha'afat Ujoor al-Waqifeen (Implementation of Benefit (Maslahah) Regarding Waqf: A Successful Avenue for the Investment of Endowments as well as Increasing the Rewards of Donors). Beirut, Lebanon: Mu'assat al-Rayyan.

al-Haneen, Muhammad. (2018). al-Wilayah wa alNazarah al-Mu'assasiyyah 'Ala al-Waqf (The Institutional Accountability and Jurisdiction Over Waqf). Riyadh, KSA: Mu'assat Sa'ee li Tatweer alAwqaf.

al-Hawrani, Yasir. (2010). Al-Mushkilat alMu'assasiyyah li al-Waqf fi al-Tajribah al-Islamiyyah al-Tarikhiyyah (The Institutional Problems of Waqf in Historical Islamic Experience). Paper presented at the 1st International Conference for the Awqaf Journal, The General Secretariat of Endowments, Kuwait .

al-Kharayyif, Rashood. (1431H). Mu'jam al-Mustalahat al-Sukkaniyyah wa al-Tanmawiyyah (A Glossary of Population and Developmental Terms). Riyadh, KSA: Mu'assasat al-Malik Khalid al-Khayriyyah (King Khalid's Charitable Organization.(

Government of KSA. (2016). Ru'yat al-Mamlakah al'Arabiyyah al-Saudia 2030 (KSA's Vision 2030). Retrieved from: http://vision2030.gov.sa/ar

al-Zarqa, Mustafa. (1419H). Ahkam al-Awqaf (The Provisions of Endowments). Amman, Jordan: Dar 'Ammar.

al-Zamee', Turki, \& al-Husaini, 'Amir. (2107). alAwqaf fi al-Mamlakah al-'Arabiyyah al-Sa'udiyyah: Ta'zeez al-Istidamah wa al-Istithmaar fi al-Mujtama' (Endowments in Saudi Arabia: Enhancing
Sustainability and Investment in Society). Riyadh, KSA: Markaz al-Buhooth wa al Tawasul al-Ma'rifi (Center for Research and Educational Communication).

al-Zaid, Abdullah. (1420H). al-Waqi' al-Mu'asir li alAwqaf fi al-Mamlakah al-'Arabiyyah al-Sa'udiyyah wa Subulu Tatweeriha (The Contemporary Status of Awqaf in the Kingdom of Saudi Arabia and Avenues for its Development). Paper published in the Conference on The Importance and Impact of Waqf on Advocacy and Development, Makkah, KSA. Makkah, KSA: Wazarat al-Shu'oon al-Islamiyyah wa al-Awqaf wa al-Da'wah wa al-Irshad (The Ministry of Islamic Affairs, Endowments, Advocacy and Guidance.(

al-Sadhan, Abdullah. (2017). al-Ri'ayah al-Ijtima'iyyah fi al-Duwal al-Khalijiyyah min al-Irtibak ila al-Ibtikar (Social Welfare in the Gulf States from Confusion to Innovation). Paper presented at the Seventh International Conference of the Faculty of Social Sciences, Kuwait University, Kuwait.

al-Sadhan, Abdullah. (2018). al-'Amal al-Kahiry alMunazzam fi al-Mamlakah al-'Arabiyyah alSa'udiyyah: Bidayaatuhu wa Mustaqbaluhu (Organized Charity Work in the Kingdom of Saudi Arabia: Its Beginnings and Future). Unpublished manuscript.

al-Saqiyyah, Ahmad. (1434H). Istithmaar al-Awqaf: Dirasah Fiqhiyyah Tatbeeqiyyah (Investing of Endowments Proceeds: An Applied Islamic Jurisprudential Study). Dammam, KSA: Dar Ibn alJawzi.

Abdullah, Tariq. (2015). Nahwa Istiratijiyyah Mutakamilah li al-Istithmarat al-Waqfiyyah: Muqarabah Ijtima'iyyah (Towards an Integrated Strategy for Endowment Investments: A Social Approach). Awqaf Journal, Kuwait, The General Secretariat of Endowments, 29, pp. 36-61.

Ghanim, Ibrahim. (1419H). al-Awqaf wa al-Siyasah fi Misr (Endowments and Politics in Egypt). Cairo, Egypt: Dar al-Shurooq.

al-Fawzan, Abdul Aziz. (1443H). Mas'oliyyat al-Dawlah fi Himayat al-Awqaf (The Responsibility of the State in the Protection of Endowments). The Justice Journal, Riyadh, KSA, Ministry of Justice, 58, pp. 109-160 .

Kamil, Abdul Aziz. (1424H). Khawatir fi al-'Omran (Thoughts on Societies). (n.p.(.

al-Lahim, Salih. (1423H). Asbab Inhisar al-Eiqaf fi al'Asr al-Hadhir (The Reasons for the Decline of Endowments in the Present Era). Paper Presented at the Conference on Waqf in Islamic Shariah and its Fields, 
The Ministry of Islamic Affairs, Endowments, Advocacy and Guidance, Riyadh, KSA.

The Awqaf Committee at the Chamber of Commerce Eastern Province. (1436H). al-Shirakah fi Majal alAwqaf (Partnership in the Field of Endowments). Dammam, KSA: Author.

The Awqaf Committee at the Chamber of Commerce, Eastern Province. (1436H). Taqreer Iqtisadiyyat alAwqaf (Report on the Economical Aspect of Endowments). Dammam, KSA: Author.

Center for Gulf and Arabian Peninsula Studies. (2016). Nadwat al-Khurooj min Daf' al-Naft: Aatharuhu alIqtisadiyyah wa al-Ijtima'iyyah wa al-Siyasiyyah (Symposium on Emerging from the Confines of Oil: Its Economic, Social and Political Implications). Series of Scientific Seminars, No. 1, Kuwait University, Kuwait.

Muslim bin al-Hajjaj (1421H). Sahih Muslim (The Authentic Traditions by Muslim). Riyadh, KSA: Darussalam.

al-Munawir, Faisal. (2014, January). Awdha' al-Ri'ayah al-Ijtima'iyyah wa Subul al-Tatweer fi Duwal Majlis al-Ta'awun al-Khaliji (The Status of Social welfare and Avenues for Its Development in the GCC Countries).
Paper presented at the Conference on the Review of the Roles and Functions of the Social Welfare Sector, its Avenues and Policies, The Executive Office of the Council of Ministers of Social Affairs of the GCC Countries, Kuwait .

al-Najjar, Abdullah. (1427H). Wilayat al-Dawlah 'Ala alWaqf: al-Mushkilaat wa al-Hulool (The State's Jurisdiction over Endowments: Problems and Solutions). Paper presented at the Second Conference on Endowments in KSA, Umm al-Quraa University, Makkah, KSA.

al-Najran, Sulaiman. (2018). al-Waqf al-Dhurri: Maqasiduhu wa wasa'ilu Islahihi (The Family Waqf: Its Objectives and Means of Reform). Riyadh, KSA: Markaz al-Istithmar al-Amthal (The Center for Optimal Investment.(

al-Namiri, Abdullah. (2016). Nizam al-Hai'ah al'Ammah li al-Awqaf wa Dawruha al-Murtaqab (The System of the General Authority for Endowments and its Expected Role). Paper presented at the Islamic Conference on Endowments, Chamber of commerce, Makkah, KSA. 
عبدالله بن ناصر السدحان حصل على الدكتوراه والماجستير في علم الاجتماع، وركز في مساره البحثي

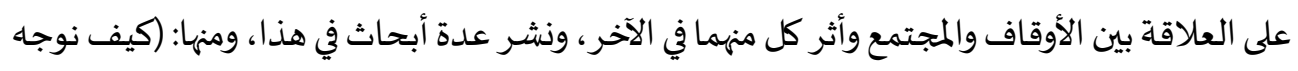
مصارف الأوقاف لتلبية احتياجات المجتمع)، و(دور الوقف في بناء الحياة الاجتماعية وتماسكها)،

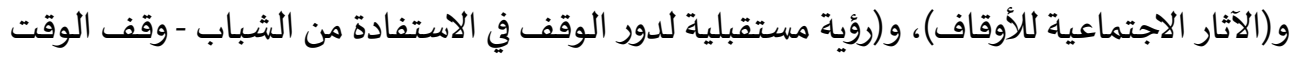

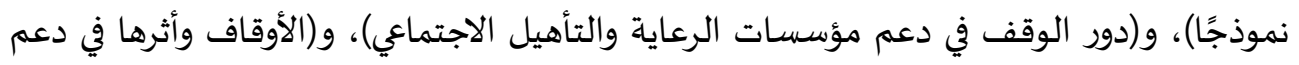
الأعمال الخيرية في المجتمح)، و(الاندثار القسري للأوقاف)، و(الصهورة الذهنية السلبية عن الأوقاف:

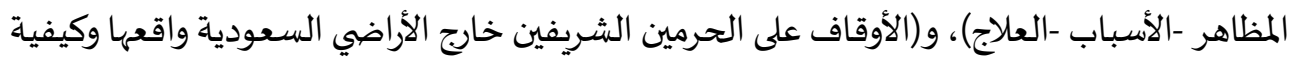

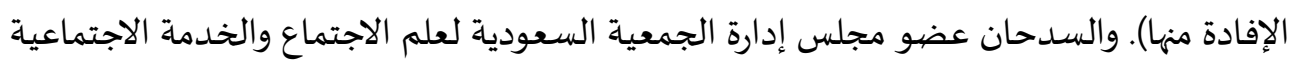

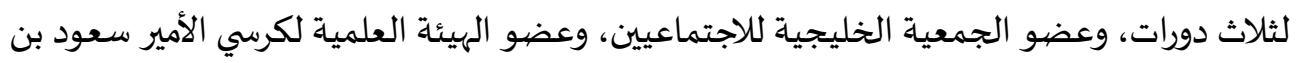

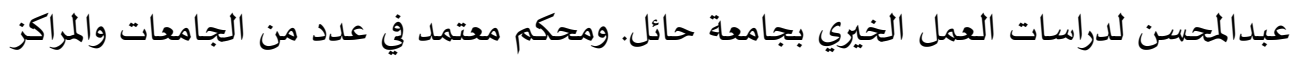

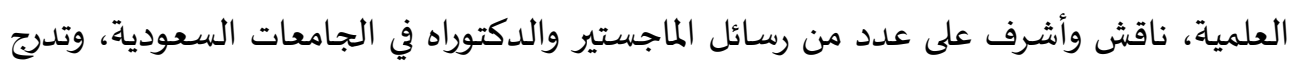

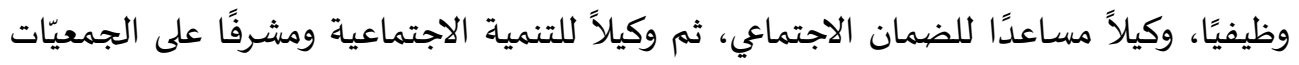

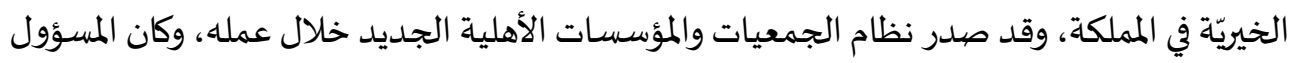
عن ملف الأوقاف في الوزارة، وهو عضو فريق الاستراتيجية الوطنية للإنماء الاجتماعي. وممثل الوزارة

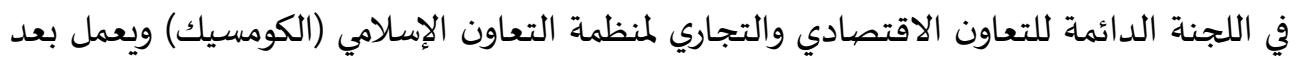

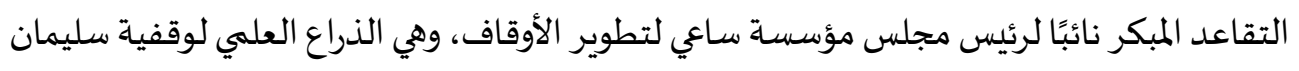
الراجحي، ومستشارًا في بعض الجهات الخيرية والوقفية. البريد الإلكتروني: ansadhan@gmail.com. 


\title{
The Role of the Waqf Declaration in Preserving Developmental Role of Awqaf
}

\author{
Abdullah Nasser Al-Sadhan \\ Deputy chairman, Governing Board, \\ Saee for Awqaf development, Riyadh, Saudi Arabia
}

\begin{abstract}
One of the most critical factors in preserving the developmental role of Awqaf is presented in this paper. The waqf declaration or document, is considered the governing bylaw which guides the present and future track of waqf for years to com. The waqf declaration needs to be articulated and written in a very robust and clear language. This paper shows some pitfalls in waqf declarations, which are usually phrased and dictated by the "Waqif (waqf's donor)" as an individual, with short sighting for future needs. The importance of phrasing and broadening the language of the declaration to make it robust against mishandling, or misinterpretation by internal or external bodies. Careful articulation of all phrases in the waqf declaration requires clear identification of the "substance of waqf", the structure of its trustees, beneficiaries, spending policies, and investments strategies. A well written waqf declaration, can only be achieved by collective efforts of experts in multidiscipline and interrelated fields like Shari'ah, management, legal, social, investment, and futuristic planners. Corrective measures from within the Waqf bodies to enhance waqf declaration is needed to regain the developmental role of waqf, along with other efforts from authorities and waqf regulating bodies.
\end{abstract}

Keywords: Waqf; Social development, Comprehensive development, Collective trustees, Individual trustee, Spending, Investment of waqf. 